\title{
UJI EFEKTIVITAS WAKTU IMPLEMENTASI ONE CARD PATIENT SEBAGAI BUSINESS PROCESS REENGINEERING SISTEM INFORMASI KLINIK DOKTER GIGI
}

\author{
Septiadi Marwan Annahar1, Irwan Budiman'2, Radityo Adi Nugroho ${ }^{3}$ \\ 1,2,3Prodi Ilmu Komputer FMIPA ULM \\ Jl. A. Yani Km 36 Banjarbaru, Kalimantan selatan \\ Email : septiadimarwan@gmail.com
}

\begin{abstract}
Generally a dentist practicing in a hospital or clinic, but for now this started many dentists who open private clinics. Currently the service system is used in every place dental clinic still manual. Less effective this system can also be seen from the process of recording patient data, transactions, computation process of goods or drugs, until the process of recording patient medical report. The resulting report was still in the form of paper are easily lost and damaged, so that the process becomes less effective service even slower. It is necessary to test the effectiveness of the time between the old system to the new system created by implementing Patient As One Card Business Process Re-Engineering dental clinics, in order to obtain a level of efficiency that can be saved in dental patient care process. From the test results based on measurement systems test the effectiveness of a comparison between the old system to the new system, the implementation of one patient cards as business process reengineering make dental clinic services to be faster.
\end{abstract}

Keywords : One Card Patient, Reengineering, Dental Clinic.

\begin{abstract}
Abstrak
Pada umumnya dokter gigi membuka praktik di rumah sakit atau poliklinik, tetapi untuk sekarang ini mulai banyak dokter gigi yang membuka klinik pribadi. Saat ini sistem pelayanan yang digunakan di setiap tempat klinik dokter gigi masih bersifat manual. Kurang efektifnya sistem ini juga dapat dilihat mulai dari proses pencatatan data pasien, transaksi-transaksi, proses perhitungan barang atau obatobatan, sampai pada proses pencatatan laporan kesehatan pasiennya. Laporan yang dihasilkan pun masih berupa kertas yang mudah hilang dan rusak, sehingga proses pelayanan menjadi kurang efektif bahkan lambat. Maka diperlukan uji efektivitas waktu antara sistem lama dengan sistem yang baru dibuat dengan mengimplementasikan One Card Patient Sebagai Rekayasa Ulang Proses Bisnis klinik gigi, demi untuk mendapatkan tingkat efisiensi waktu yang di bisa dihemat pada proses pelayanan pasien gigi. Dari hasil pengujian berdasarkan sistem pengukuran uji efektivitas waktu membandingkan antara sistem lama dengan sistem yang baru, implementasi one card patient sebagai business process reengineering membuat pelayanan klinik gigi menjadi lebih cepat.
\end{abstract}

Kata kunci : One Card Patient, Rekayasa Ulang, Klinik Gigi 


\section{PENDAHULUAN}

Klinik gigi pada perkembangan yang terjadi pada masa kini, banyak masyarakat mendatangi dokter gigi bukan hanya untuk kesehatan tapi juga untuk kepentingan estetika kecantikan. Pada umumnya dokter gigi membuka praktik di rumah sakit atau poliklinik, tetapi untuk sekarang ini mulai banyak dokter gigi yang membuka praktik pribadi. Dalam praktik dokter gigi tentunya memiliki beberapa transaksi yang harus ditangani. Dimana transaksi tersebut membutuhkan pencatatan dan pengolahan data dengan baik. Bila pasien berobat ke dokter lain pun, maka akan dibuatkan riwayat berobat pasien yang baru dan tidak meng-update data riwayat yang terdapat pada dokter sebelumnya. Bila hal ini terjadi, maka setiap pasien yang berobat di tempat praktik lain harus menceritakan kembali riwayat berobat sebelumnya dan proses pelayanan akan menjadi lebih lambat.

Menurut Annahar[1], saat ini sistem pelayanan yang digunakan di setiap tempat klinik dokter gigi masih bersifat manual. Kekurangan efektifnya sistem ini juga dapat dilihat mulai dari pencatatan data pasien, transaksi-transaksi, proses perhitungan barang atau obat-obatan, sampai pada proses pencatatan laporan kesehatan pasiennya. Laporan yang dihasilkan pun masih berupa kertas yang mudah hilang dan rusak, sehingga proses pelayanan menjadi lambat bahkan kurang efektif.

Berdasarkan uraian tersebut maka diperlukan uji efektivitas waktu antara sistem lama dengan sistem yang baru untuk mendapatkankan tingkat efisiensi waktu yang bisa di hemat pada pelayanan pasien gigi dengan implementasikan one card patient sebagai rekayasa ulang proses bisnis yang dapat menjadikan proses pelayanan menjadi cepat lebih.

\section{METODE PENELITIAN}

Berikut contoh sikuls dalam tahapan dalam business process reengineering seara umum yaitu:
a. Identifikasi proses (Identify process)
b. Update analisis
c. Desain
d. Testing dan Implementasi

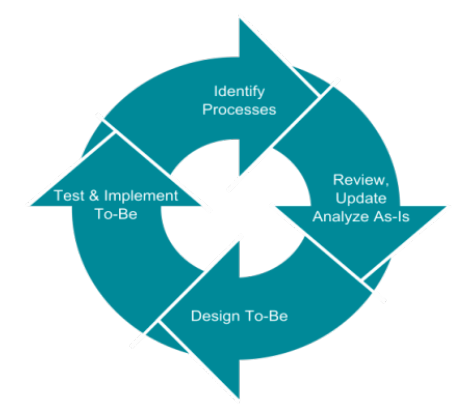

Gambar 1. Siklus business process reengineering (BPR). Sumber : Reenginnering is the fundamental rethinking and radical design of business.1995 


\subsection{Kondisi Eksisting Proses Bisnis}

Tahapan awal ini dilakukan untuk memahami masalah apa saja yang terjadi terhadap proses-proses yang sedang berlangsung, dengan merencanakan interaksi dari unit yang melakukan proses produksi pada organisasi, kemudian mengidentifikasi serta mengevaluasi proses yang terjadi saat ini.

\subsection{Update Proses Bisnis}

Pada tahap ini yaitu menghilangkan semua kendala yang ada dan membuat proses yang baru untuk mendapatkan tingkat efektivitas waktu yang bisa dihemat.

\subsection{Sistem Pengukuran}

Manager fungsional harus tahu pengukuran penting terhadap kinerja yang akan digunakan untuk menilai keberhasilan dari upaya perbaikan. Pengukuran dapat dilakukan dengan menguji efektivitas waktu, yang artinya membandingkan waktu dari proses sebelumnya dengan proses yang baru direkayasa ulang prosesnya.

\section{HASIL DAN PEMBAHASAN}

\subsection{Uji Efektivitas Waktu}

Sistem ini harus dilakukan agar kita bisa tahu pengukuran penting terhadap kinerja yang akan digunakan untuk menilai keberhasilan dari upaya perbaikan. Pengukuran dilakukan dengan kinerja kecocokan terhadap tujuan seperti uji coba efektivitas waktu.

\subsubsection{Kondisi Eksisting Proses Bisnis}

Merupakan langkah awal yang dilakukan adalah mendokumentasikan proses yang sedang berlangsung dapat dilakukan dengan merencanakan interaksi dari unit yang melakukan proses. Sistem pelayanan dapat digambarkan pada tahap proses bisnisnya maupun dalam bentuk flowchat.

a. Proses Bisnis

Berikut ini adalah proses bisnis praktek dokter gigi yang berlangsung di wilayah Kota Banjarbaru :

1) Dokter gigi melakukan registrasi dibutuhkan waktu 5 menit

2) Asisten melakukan registrasi dibutuhkan waktu 5 menit

3) Pasien berkunjung ke tempat praktek gigi dan dan menunjukan kartu statusnya beserta nomor pasiennya, jika belum punya kartu status maka harus registrasi family dan pasien terlebih dahulu. Membutuhkan waktu hingga 10 menit

4) Jika pasien sudah mempunyai kartu status, maka langsung registrasi checkup saja dan itu membutuhkan waktu 5 menit

5) Pada proses berikutnya dokter melakukan pemeriksaan terlebih dahulu setelah itu melihat rekam medis pasien, waktu yang di capai sekitar 5 menit

6) Setelah itu dokter melihat data riwayat penyakit pasien, waktu ditempuh 10 menit 
7) Baru dilanjutkan dengan proses menambah data rekam medis baru, waktu yang tempuh sekitar 5 menit

8) Pada proses berikutnya dokter yang lupa dengan kode rekam medis melihat kode nama penyakit, waktu yang dicapai 8 menit

9) Selesai melakukan pemeriksaan dokter membuat/menulis rekam medis baru pada kartu status pasien yang kemudian membuatkan resep obat untuk pasien dengan waktu 4 menit.

10) Jika dokter gigi meihat laporan kunjungan pasien maka proses tersebut cukup lama untuk dilakukan sekitar 20 menit

11) Sama halnya jika dokter gigi ingi melihat laporan data rekam medis pasien, dibutuhkan waktu yang lama sekitar 20 menit juga.

b. Flowchart Alur Proses Inti Klinik Gigi

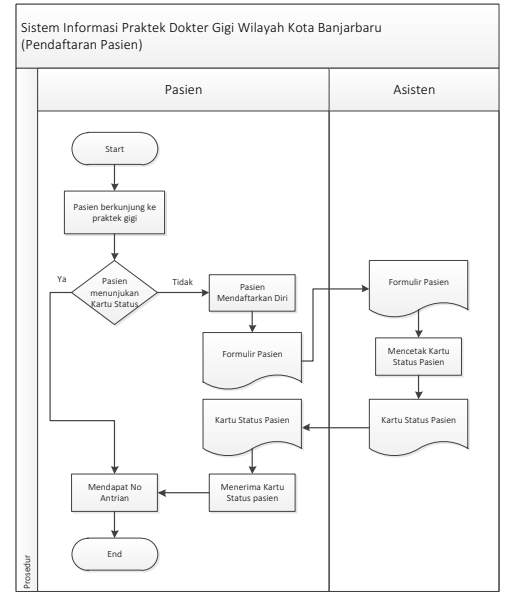

(a)

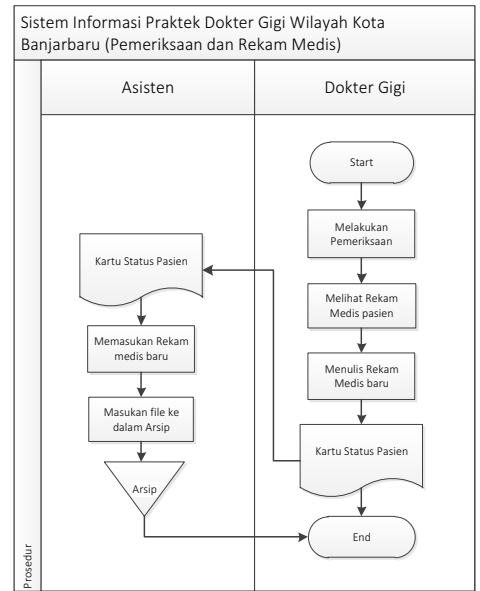

(b)

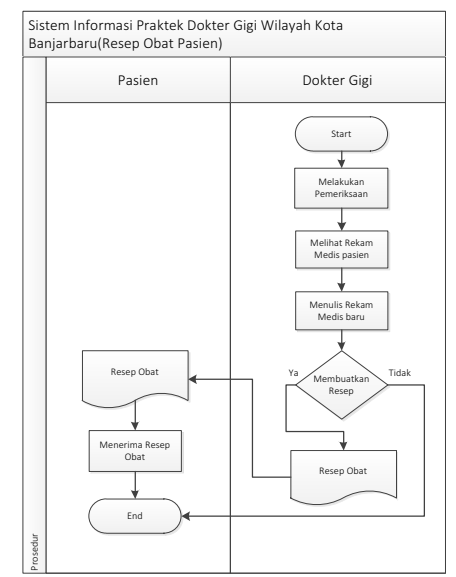

(c)

Gambar 2. Flowchart Alur proses : (a) Registrasi pasien, (b) Pemeriksaan dan rekam medis, (c) Resep obat pasien.

Sumber : Uji Efektivitas Waktu Implementasi One Card Patient Business Process Reengineering Sistem Informasi Klinik Gigi. 2016 


\subsubsection{Update Proses Bisnis}

Tahap ini merupakan tahap kritis dimana pertanyaaan dan asumsi pada proses sebelumnya diuji, menghilangkan semua kendala yang ada dalam pencarian suatu proses yang lebih baik.

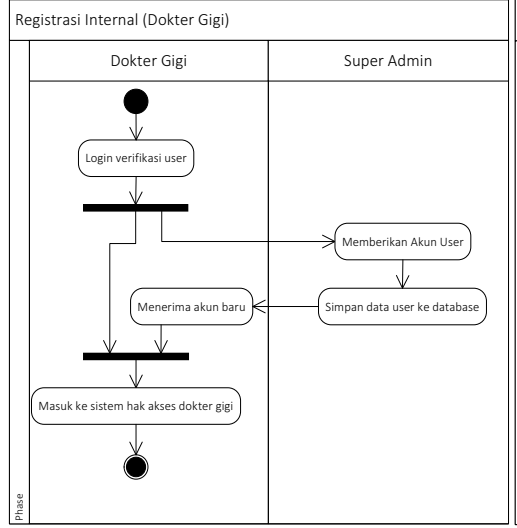

(a)

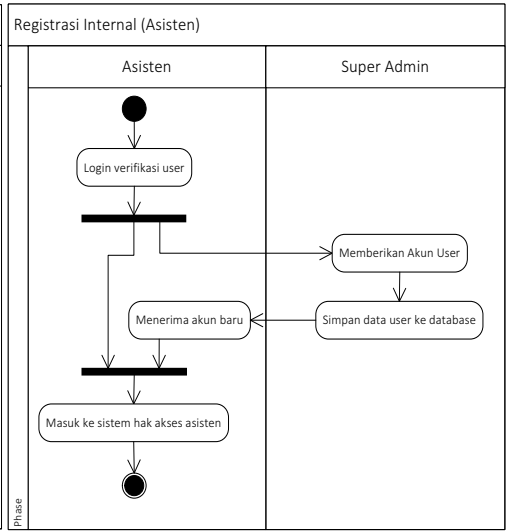

(b)

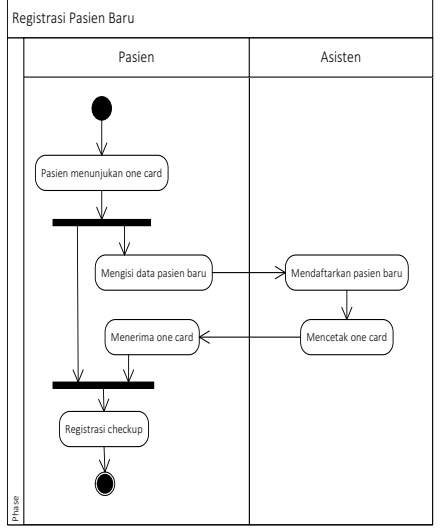

(c)

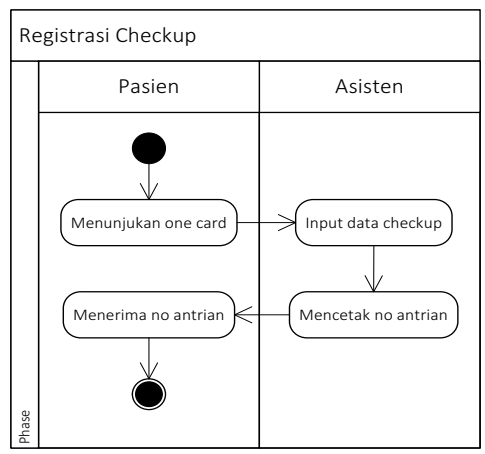

(d)

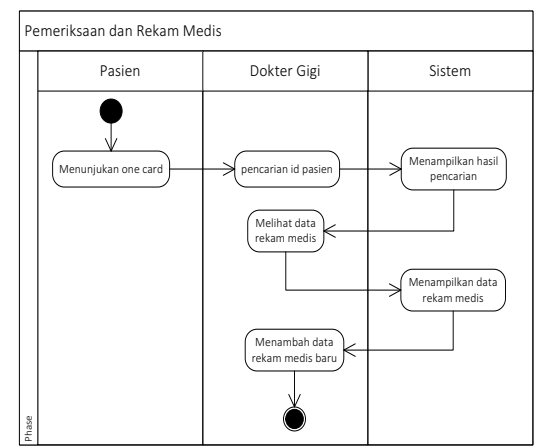

(e)

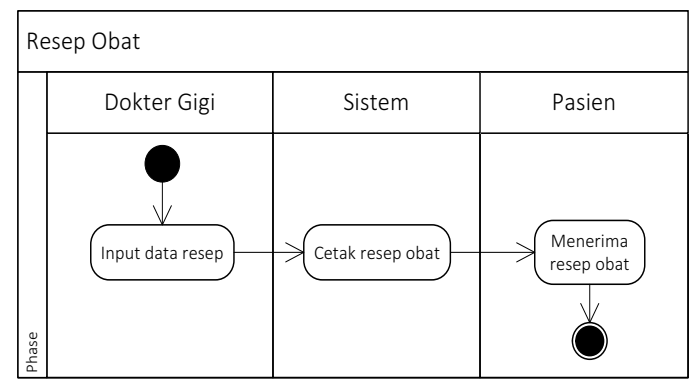

(f)

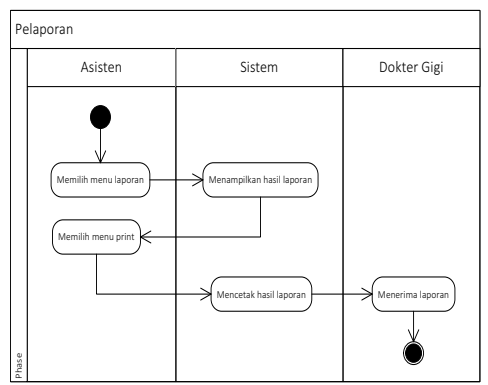

(g)

Gambar 3. Activity diagram alur : (a) Registrasi internal dokter gigi, (b) Registrasi internal asisten, (c) Registrasi pasien baru, (d) Registrasi checkup, (e) Pemeriksaan dan rekam medis, (f) Resep obat, (g) Pelaporan

Sumber : Uji Efektivitas Waktu Implementasi One Card Patient Business Process Reengineering Sistem Informasi Klinik Gigi. 2016 


\subsubsection{Sistem Pengukuran}

Uji coba efektivitas waktu merupakan suatu pengujian perbandingan waktu antara sistem yang lama dengan sistem yang baru pada sebuah proses bisnis yang direkayasa ulang, demi untuk mendapatkan tingkat waktu yang efisiensi pada suatu proses bisnis. Perbandingan waktu dilakukan pada setiap nama proses, dan nanti menghasilkan dalam bentuk persen (\%) yang artinya tingkat efisiensi waktu yang di hemat berapa persen.

Terdapat beberapa proses lama yang sedang berlangsung saat ini di praktik gigi yang perlu diperhatikan, diantaranya proses registrasi dokter gigi yang diisi masih secara manual sama seperti halnya registrasi asisten dan itu masih dalam bentuk arsip. Kemudian registrasi family, registasi pasien dan registrasi checkup juga masih secara manual tidak secara komputerisasi yang membuat proses pelayanan menjadi lamban, berikutnya ada proses pemeriksaan dan rekam medis yang meliputi proses melihat riwayat penyakit pasien maupun menambah rekam medis baru hingga pemberian resep obat juga dilakukan secara manual, dan data rekam medis disimpan dalam bentuk arsip. Proses akhir yaitu pelaporan kunjungan pasien dan rekam medis pasien yang masih dalam bentuk arsip, sehingga dibutuhkan waktu yang cukup lama dalam proses pelaporannya.

Pada proses yang baru, waktu yang didapatkan dalam skala menit pada tiaptiap proses itu berdasarkan pemantauan dalam beberapa hari. Sistem yang telah dipasang kemudian dikerjakan oleh pengguna sistem, dari situ pemantauan dilakukan pada tiap-tiap proses mulai dari registrasi dokter gigi, pasien, rekam rekam medis sampai pencetakan laporan. Pemantauan dilakukan beberapa hari dengan cara mencatat waktu yang di tempuh pada setiap proses dengan menggunakan stopwatch sebagai alat penghitung waktu demi untuk mendapatkan waktu yang signifikan pada tiap prosesnya.

Table 1. Uji coba efektivitas waktu

\begin{tabular}{|c|c|c|c|c|c|}
\hline No & Nama Proses & $\begin{array}{l}\text { Waktu Proses } \\
\text { Yang Lama } \\
\text { (menit) }\end{array}$ & $\begin{array}{c}\text { Waktu } \\
\text { Proses Yang } \\
\text { Baru (menit) }\end{array}$ & $\begin{array}{c}\text { Perbedaan } \\
\text { Waktu } \\
\text { (menit) }\end{array}$ & $\begin{array}{c}\text { Tingkat } \\
\text { Efisiensi } \\
\text { Waktu Yang } \\
\text { Dihemat (\%) }\end{array}$ \\
\hline 1 & Registrasi Dokter Gigi & 5 & 2 & 3 & $60 \%$ \\
\hline 2 & Registrasi Asisten & 5 & 2 & 3 & $60 \%$ \\
\hline 3 & Registrasi Family & 10 & 5 & 5 & $50 \%$ \\
\hline 4 & Registrasi Pasien & 10 & 3 & 7 & $70 \%$ \\
\hline 5 & $\begin{array}{l}\text { Registrasi Checkup } \\
\text { Pasien }\end{array}$ & 5 & 1 & 4 & $80 \%$ \\
\hline 6 & $\begin{array}{l}\text { Melihat Data Rekam } \\
\text { Medis }\end{array}$ & 5 & 1 & 4 & $80 \%$ \\
\hline 7 & $\begin{array}{l}\text { Melihat Riwayat } \\
\text { Penyakit Pasien }\end{array}$ & 10 & 2 & 8 & $80 \%$ \\
\hline 8 & $\begin{array}{l}\text { Menambah Rekam } \\
\text { Medis }\end{array}$ & 5 & 3 & 2 & $40 \%$ \\
\hline 9 & $\begin{array}{l}\text { Melihat Kode Nama } \\
\text { Penyakit }\end{array}$ & 8 & 2 & 6 & $75 \%$ \\
\hline
\end{tabular}




\begin{tabular}{|c|c|c|c|c|c|}
\hline No & Nama Proses & $\begin{array}{l}\text { Waktu Proses } \\
\text { Yang Lama } \\
\text { (menit) }\end{array}$ & $\begin{array}{c}\text { Waktu } \\
\text { Proses Yang } \\
\text { Baru (menit) }\end{array}$ & $\begin{array}{c}\text { Perbedaan } \\
\text { Waktu } \\
\text { (menit) }\end{array}$ & $\begin{array}{c}\text { Tingkat } \\
\text { Efisiensi } \\
\text { Waktu Yang } \\
\text { Dihemat (\%) }\end{array}$ \\
\hline 10 & Resep Obat & 4 & 1 & 3 & $75 \%$ \\
\hline 11 & $\begin{array}{l}\text { Pelaporan Kunjungan } \\
\text { Pasien }\end{array}$ & 20 & 2 & 18 & $90 \%$ \\
\hline 12 & $\begin{array}{l}\text { Laporan Data Rekam } \\
\text { Medis }\end{array}$ & 20 & 2 & 18 & $90 \%$ \\
\hline
\end{tabular}

Sumber : Uji Efektivitas Waktu Implementasi One Card Patient Business Process Reengineering Sistem Informasi Klinik Gigi. 2016

Table 2. Uji T(test)

\begin{tabular}{ccc}
\hline No & Sistem Lama (SL) & Sistem Baru (SB) \\
\hline 1. & 5 Menit & 3 Menit \\
2. & 5 Menit & 3 Menit \\
3. & 10 Menit & 5 Menit \\
4. & 10 Menit & 3 Menit \\
5. & 5 Menit & 1 Menit \\
6. & 5 Menit & 1 Menit \\
7. & 10 Menit & 2 Menit \\
8. & 5 Menit & 3 Menit \\
9. & 8 Menit & 2 Menit \\
10. & 4 Menit & 1 Menit \\
11. & 20 Menit & 2 Menit \\
12. & 20 Menit & 2 Menit \\
\hline
\end{tabular}

Sumber : Uji Efektivitas Waktu Implementasi One Card Patient Business Process Reengineering Sistem Informasi Klinik Gigi. 2016

Uji T satu sempel digunakan untuk menguji apakah rata-rata satu sampel berbeda atau sama dengan suatu nilai tertentu yang digunakan sebagai pembanding. perhitungan dilakukan dengan membuat uji $t$ pada SPSS menggunakan "compare means".

\begin{tabular}{|c|c|c|c|c|}
\hline & SL & SB & var & var \\
\hline 1 & 5 & 3 & & \\
\hline 2 & 5 & 3 & & \\
\hline 3 & 10 & 5 & & \\
\hline 4 & 10 & 3 & & \\
\hline 5 & 5 & 1 & & \\
\hline 6 & 5 & 1 & & \\
\hline 7 & 10 & 2 & & \\
\hline 8 & 5 & 3 & & \\
\hline 9 & 8 & 2 & & \\
\hline 10 & 4 & 1 & & \\
\hline 11 & 20 & 2 & & \\
\hline 12 & 20 & 2 & & \\
\hline
\end{tabular}

Gambar 4. Data View pada SPSS

Sumber : Uji Efektivitas Waktu Implementasi One Card Patient Business Process Reengineering Sistem Informasi Klinik Gigi. 2016 


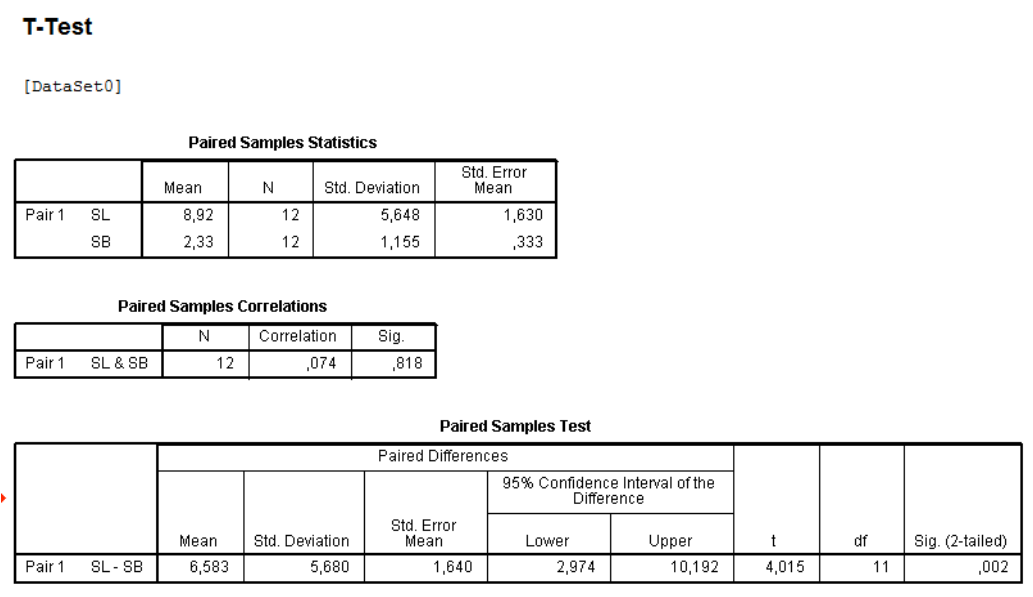

Gambar 5. Hasil Output Uji T

Sumber : Uji Efektivitas Waktu Implementasi One Card Patient Business Process Reengineering Sistem Informasi Klinik Gigi. 2016

Berdasarkan gambar 4 dan gambar 5 dapat dijelaskan beberapa tahap dalam pengujian yaitu :

a. Hipotesis

Seperti untuk kasus ini, hipotesis yang diambil adalah

1) Ho = Rata-rata waktu antara sistem lama dengan sistem baru adalah sama atau tidak berbeda secara nyata

2) $\mathrm{H}_{\mathrm{A}}=$ Rata-rata waktu antara sistem lama dengan sistem baru adalah tidak sama atau berbeda secara nyata

b. Pengambilan Keputusan

Dasar pemngambilan keputusan :

1) Berdasarkan $T$ hitung dengan $T$ tabel

a) Jika statistik dihitung ( $\mathrm{T}$ hitung $>\mathrm{T}$ tabel), Ho ditolak

b) Jika statistik dihitung (T hitung $<\mathrm{T}$ tabel), Ho diterima

$\mathrm{T}$ hitung dari output statistik di atas tersebut adalah $\mathrm{t}=4,015$ sedangkan $\mathrm{T}$ tabel berdasarkan $\mathrm{df}$ (degree of freedom) derajat kebebasan : jumlah data -1 atau $12-1=11(\mathrm{~T}$ tabel $=1,7959)$

2) Berdasarkan nilai signifikansi :

a) Jika probabilitas $>0,05$, Ho di terima

b) Jika probabilitas $<0,05$, Ho ditolak

c. Kesimpulan

Terlihat bahwa $\mathrm{T}$ hitung adalah $\mathrm{t}=4,015$ dengan probabilitas 0,002 oleh karena $\mathrm{T}$ hitung lebih besar dari $\mathrm{T}$ tabel, maka Ho ditolak. Demikian juga dilihat dari nilai probabilitasnya yang lebih kecil dari 0,05 , maka Ho ditolak. Dengan kata lain dapat disimpulkan bahwa, rata-rata waktu antara sistem lama dengan sistem baru adalah tidak sama atau berbeda secara nyata. 


\subsection{Manfaat One Card Patient}

Pemanfaatan one card patient agar dapat memberikan data dan informasi yang lengkap guna membantu rekam medis praktik dokter gigi yaitu terletak pada desain one card itu sendiri.

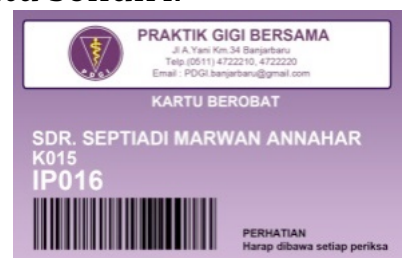

(a)

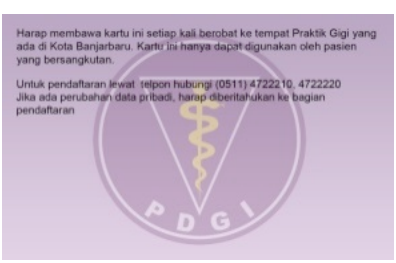

(b)

Gambar 6. Desain kartu pasien (a) Tampak depan, (b) Tampak belakang Sumber : Uji Efektivitas Waktu Implementasi One Card Patient Business Process Reengineering Sistem Informasi Klinik Gigi. 2016

Dari tampak depan desain one card patient terdapat beberapa keterangan, pada bagian header kartu tertera alamat tempat praktik, nomor telepon serta email. Dilanjutkan pada bagian isi kartu yang merupakan inti dari one card patient itu sendiri terdapat nama pemilik one card atau bisa dikatakan pasien gigi, kemudian "K015" menunjukan bahwa itu adalah kode family pasien, dari kode itu pihak dokter dapat mengakses data family si pasien. Sedangkan "IP016" adalah id pasien itu sendiri, dari id pasien itu juga pihak dokter dapat mengakses data dan informasi pasein yang ada pada sistem mulai dari biodata pasien hingga rekam medis pasien.

Manfaat one card patient sendiri bagi pasien yang memiliki, mereka tidak perlu lagi untuk registrasi selayaknya pasien baru, hanya melakukan registrasi ulang saja untuk mendapatkan nomor antrian, pasien pun tidak perlu lagi menceritakan riwayat penyakitnya karena sudah memilki data history yang ada.

\subsection{Rekayasa Ulang Menjadi Solusi}

Rekayasa ulang proses bisnis yang dilakukan agar sistem informasi ini dapat menjadi solusi dalam pelayanan praktik gigi yang lebih cepat, maka dilakukan mulai dari analisis eksisting yang dimana tahap itu memahami atau mengerti kondisi yang terjadi. Maksud dari pernyataan tersebut kita harus memahami betul permasalahan pada proses pelayananya praktik gigi yang ada, mulai dari registrasi pasien hingga data rekam medis pasien tersebut. Kemudian berpikir kritis untuk mencari alternatif rancangan ulang dan memenuhi informasi apa saja untuk mendukung proses sistem informasi, hal tersebut dilakukan dengan analisis proses yang di tawarkan dengan merancang sebuah proses yang baru dengan menggunakan tools activity diagram sebagai jalannya program.

Dilakukannya pengujian dengan menguji coba efektivitas waktu yang terdapat dalam sistem pengukuran, untuk mengetahui berhasil tidaknya dengan solusi proses rekayasa ulang dalam pelayanan yang lebih cepat bagi pasien gigi. Pada sistem pengukuran dengan menguji coba efektivitas waktu, dimana uji coba ini dengan membandingkan lamanya proses pelayanan praktik gigi antara sistem yang lama dengan sistem yang baru. Perbandingan dilakukan pada tiap-tiap proses praktik gigi, dari registrasi pasien sampai pasien menerima resep obat dari dokter 
gigi. Semua proses itu di lakukan sendiri oleh pihak pengguna sistem dengan pemantauan secara langsung selama beberapa hari dan pencatatan waktu lamanya saat menggunakan sistem yang baru di buat, cara ini dilakukan guna untuk mendapatkan waktu yang secara signifikan atau bisa dikatakan tingkat efektivitas waktu yang dihemat. Hasil dari perbandingan dinyatakan dalam bentuk persen (\%) yang artinya seberapa besar tingkat efisensi waktu yang dihemat dengan cara perbedaan waktu di bagi dengan waktu proses pada sistem yang lama, maka itulah hasil yang didapat pada tingkat efesiensi waktu yang dihemat tiap-tiap proses pelayanan praktik gigi tersebut. Dapat terlihat juga dilakukan pengujian menggunakan SPSS dengan melakukan Uji T(test), dengan memasukan data sistem lama (SL) dan sistem baru (SB) terlihat bahwa $\mathrm{T}$ hitung adalah $\mathrm{t}=4,015$ dengan probabilitas 0,002 oleh karena $\mathrm{T}$ hitung lebih besar dari $\mathrm{T}$ tabel, maka Ho ditolak. Dapat dilihat juga dari nilai probabilitasnya yang lebih kecil dari 0,05 , maka Ho ditolak. Dengan kata lain, membuktikan bahwa rata-rata waktu antara sistem lama dengan sistem baru adalah tidak sama atau berbeda secara nyata.

\section{SIMPULAN}

Dari hasil penelitian yang telah dilakukan, dapat diambil simpulan bahwa, berdasarkan sistem pengukuran uji efektivitas waktu rekayasa ulang proses bisnis dengan membuat one card patient sebagai solusi, maka tingkat efisiensi waktu bisa dihemat dan dapat menjadi lebih cepat pada proses pelayanan klinik dokter gigi.

\section{DAFTAR PUSTAKA}

[1] Annahar, Septiadi Marwan. 2016. One Card Patient Sebagai Rekayasa Ulang Proses Bisnis Praktik Dokter Gigi di Wilayah Kota Banjarbaru. Program S-1 Ilmu Komputer, Universitas Lambung Mangkurat: Banjarbaru.

[2] Association for Dental Education in Europe (ADEE). 2004. Profile and Competences for the European Dentist.

[3] El-Sawy, 2002. Redesign Enterprise Processes for e-Business. New York: McGraw-Hill.

[4] Hammer, Michael.1995. Reenginnering is the fundamental rethinking and radical design of business, ( $\mathrm{P} 32$ ).

[5] Kair, Abdul. 2009. Pengenalan Sistem Informasi. Yogyakarta: Andi.

[6] Parno, S.Kom. MMSI. 2009. Sistem Informasi (Data Flow Diagram). Jakarta

[7] Muljo, Hery H., Darmadi, H., dan Setiawan, J. 2008. Sistem informasi pelayanan terpadu. Jurnal Piranti Warta, 11(3).

[8] Salemba Humanika, Nisfiannoor, Muhammad. 2009. Pendekatan Statistika Modern Untuk Ilmu Social "Statistical Product and Service Solution". Modul Pembelajaran SPSS, (15) 